6. Obesity: etiology, pathogenesis, clinical aspects / ed. I.I. Dedova, G.A. Melnichenko. M .: MIA. - 2006. P. 452

7. Radaeva M.V. The state of lipid peroxidation and antioxidant system as a measure of the effectiveness and safety of ozonotherapy / M.V. Radaeva, K.N. Kontorschikova, E.F. The Queen // Kazan Medical Journal. -2007. - № 4. - v. 88,

8. Radaeva M.V. The activity of antioxidant enzymes in normal and oxidative stress is exemplified by the metabolic syndrome. The thesis abstract of Cand. Biol. sciences. N. Novgorod. 2008. - 27 with.

9. Chazova, IE Metabolic syndrome / IE Chazova, VB Mychka. - M.: Media Medica, 2004. - C. 23-24.

10. Blaak E.E. Metabolic fluxes in skeletal muscle in relation to obesity and insulin resistance // Best Pract. Res. Clin. EndocrinolMetab. 2005. - Vol. 19 (3): P. 391403

11. Cahova M, Vavrinkova H, Kazdova L. Glucose-fatty acid interaction in skeletal muscle and adipose tissue in insulin resistance // Physiol. Res. 2007. - Vol. 56. -P. 1-15

12. Meigs J.B., Rutter M.K., Sullivan L.M., Fox C.S., D'Agostino R.B., Wilson P.W.F. Impact of insulin resistance on the face of metabolic syndrome. 2 Diabetes Care. 2007. - Vol. 30. - P. 1219-1225

13. Reaven G. M. The metabolic syndrome: is this diagnosis necessary? // Am. J. Clin.Nutr.-2006-Vol. 83.-P. 1237-1247

14. Sarti C, Gallagher J. The metabolic syndrome: prevalence, CHD risk, and1 treatment // J. Diabetes Complications. 2006. - Vol. 20. - P. 121-132

\title{
Moskalets O.V. \\ Potential predictors of outcomes of exudative inflammatory reaction in pseudophakia
} Moscow Regional Research Clinical Institute named after M.F.Vladimirskij

(Russia, Moscow)

doi 10.18411/gq-30-11-2019-09

idsp sciencerussia-30-11-2019-09

Introduction. Despite the introduction of minimally invasive surgical technologies, the use of modern biocompatible materials and drugs, the problem of exudative-inflammatory reactions (EVR) of the eye that occur after implantation of intraocular lenses (IOLs) is still relevant. Their frequency ranges from $3.1 \%$ to $13 \%$ [1]. There are infectious EVR caused by different microorganisms, and non-infectious, caused by the reaction of tissues to the surgical trauma itself, IOL or consumables. The timing of the development of EVR ranges from several days to a month or more after surgery. The most severe manifestation is endophthalmitis, which can result in removal of the eye [4]. Predicting the course and outcome of EVR is quite difficult, therefore, the search for laboratory markers that allow this to be done seems quite relevant. Potential candidates include various markers of inflammation and endothelial disfunction, as well as autoantibodies [2,3,5].

The aim of this study was to identify laboratory markers characteristic of various types of EVR in case of pseudophakia.

Material and methods. The study included 21 patients (9 men and 12 women) aged 17 to 69 years with an EVR that developed after phacoemulsification followed by implantation of an IOL. Laboratory studies were performed upon admission to the hospital and before discharge and included bacterial culture from the conjunctival cavities of both eyes, determination of the level of neopterin, antibodies to double-stranded DNA (anti-DNA), soluble adhesion molecules (sICAM-1, sVCAM-1). Subsequently, patients were monitored for 6 months. We used test systems from IBL (Austria), Orgentec (Germany), Bender MedSystems (Austria)

Results. EVR occurred in all patients at different times after surgery (from 2 to 14 days). The severity of EVR distribution was as follows: II degree -8 patients $(38.1 \%)$, III degree -11 patients $(52.3 \%)$, IY degree - 3 patients $(14.3 \%)$.

The initial levels anti-DNA was increased in $12(57.1 \%)$ patients, neopterin in 9 (42.8\%), sICAM-1 in 3 (14.3\%), sVCAM-1 in 5 (23, 8\%). Reliable correlations with the timing of the development of EVR and its severity were not obtained. Large individual fluctuations of indicators were noted. 
When studying these indicators in dynamics, it was found that normalization of antiDNA levels occurred in 6 patients, while in 5 it significantly decreased compared to the initial level. At the same time, in 1 patient with severe postoperative endophthalmitis, this indicator increased even more, which can be explained by an increase in apoptosis processes.

Normalization of neopterin levels occurred in 6 patients, in 2 it remained elevated. At the same time, in 1 patient, this indicator before discharge from the hospital increased significantly compared to the initial normal value, although the course of the disease was favorable and no complications and relapses were noted in the future.

Patient monitoring revealed the following. In 1 patient with endophthalmitis, the most unfavorable outcome was eye removal. At the same time, he also had the highest initial level of sVCAM-1 (3472 ng / ml), a high level of neopterin (20.6 nmol / L), both of which rapidly increased. The second patient with endophthalmitis had an initially high level of anti-DNA; before discharge, it increased by almost 5 times, but the remaining indicators practically did not exceed normal values. The course of the disease was protracted, but in the end, the outcome was favorable. Finally, in the third patient, admission showed rather high levels of antibodies to nDNA $(93.5 \mathrm{U} / \mathrm{ml})$ and neopterin $(27.7 \mathrm{ng} / \mathrm{ml})$, but by the end of treatment they returned to normal, which coincided with positive clinical dynamics. No further relapses were noted. Vision loss as the outcome of acute uveitis was associated with a high level of sICAM-1 (610 ng / ml), a moderate increase in neopterin and antibodies to nDNA upon admission. At the same time, a moderate increase in the level of sVCAM-1 was noted in the dynamics. Also noteworthy is the case when a patient with acute uveitis, normal and favorable course of the postoperative period after 1.5 months. severe endophthalmitis developed, requiring repeated hospitalization and prolonged drug therapy.

$$
* * *
$$

1. Belousova N.Ju. Exudative-inflammatory reaction of the eye in cataract surgery: a modern view of the problem. Modern technology in medicine. 2011. 3; 134-141(in Russ.).

2. Krichevskaya G.I., Likhvantseva V.I., Angelov V.O. The value of autoimmune reactions in the development of postoperative uveitis in patients with artifakia. Bulletin of Ophthalmology.1996. 5; 27-29 (in Russ.).

3. Moskalets O.V. Molecules of cellular adhesion ICAM-1 and VCAM-1 in infectious pathology. Pacific Medical J. 2018. 2;21-25 (in Russ.).

4. Arijeet D. Endophthalmitis after cataract surgery. Ophthalmology. 2010. 117(4); 853-859.

5. Kooij B., Rothava A., Rijkers G., deGroot Mijness J.D. Distinct cytokine and chemokine profiles in the aqueous of patients with uveitis and cystoid macular edema. AM. J. Ophthalmol. 2006. $142(1) ; 192-194$.

\section{Moshkova A.I., Levanov V.M. \\ Information Technologies Application and Growing Digitation in Dental Practice in the Russian Federation \\ FSBE Institution of Higher Education "Privolzhsky Research Medical University” of the Ministry of Health of the Russian Federation \\ (Nizhniy Novgorod, Russia)}

doi 10.18411/gq-30-11-2019-10

idsp sciencerussia-30-11-2019-10

Research Relevance. Nowadays, the information technologies progress reflects the social outlook. "Digital Health" is the project realized in Russia as part of the "Digital Economy" program. This project is looking to build a new health model on the grounds of the information systems' pecking order, launching new technologies along with modern management methods [10]. Taking into account constantly growing dental diseases as well as high dentist attendance, the dentist service is completely involved health digitation processes. Apart from that the information and telecommunication services (ITS) are integrated into both 